\title{
Programmable nanodisc patterning by DNA origami
}

\author{
Zhao Zhang, Edwin R. Chapman
}

Howard Hughes Medical Institute, Department of Neuroscience, University of Wisconsin-Madison, 1111 Highland Avenue, Madison, Wisconsin 53705, USA.

\section{Supporting Information}




\section{TABLE OF CONTENTS}

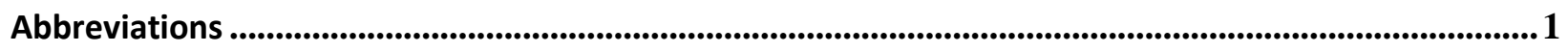

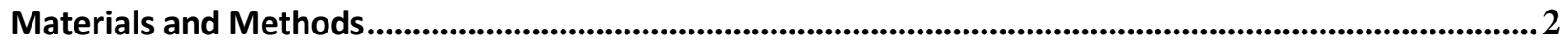

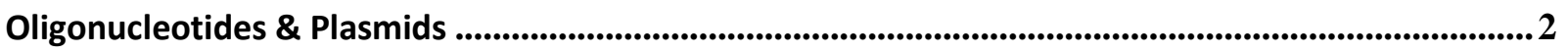

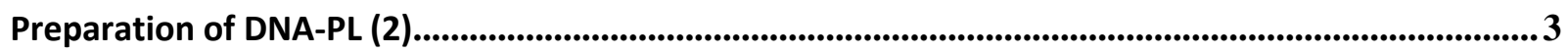

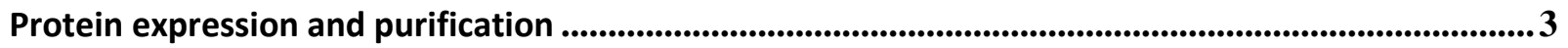

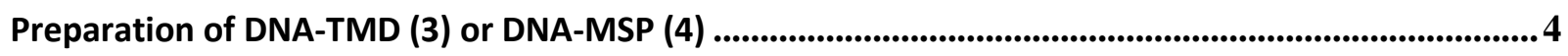

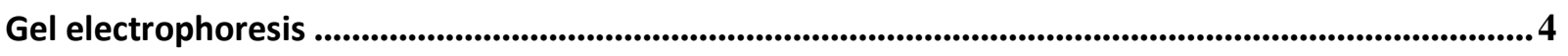

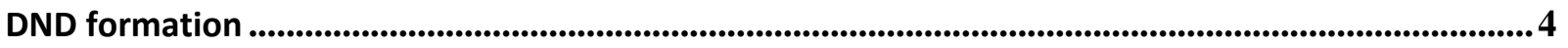

DNA origami design and preparation ...............................................................................................................5

Origami-directed DND patterning ........................................................................................................................5

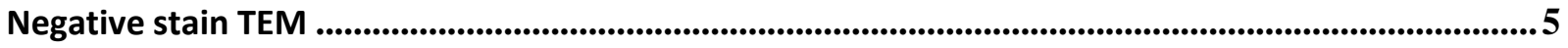

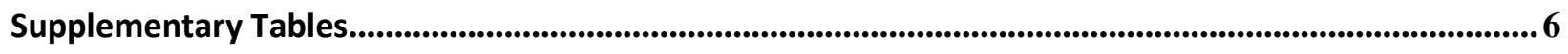

Table S1. Attachment yield and specificity of single DNDs on V-origami. ...........................................6

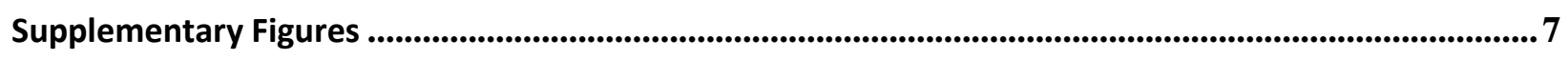

Figure S1. TEM images of DNDs...........................................................................................................

Figure S2. TEM images of DND on V-origami for yield analysis.....................................................

Figure S3. Schematics of DNA origami design. ...............................................................................................9

Figure S5. Comparison of DND with 5'- and 3'- modified oligos attaching to V-origami. ....................11

Figure S6. TEM images of DNA nanocages with control DNDs. ..................................................12

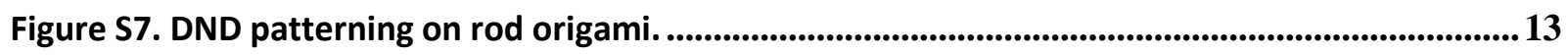

Figure S8. DND-mediated rod assembly.................................................................................................... 14

Figure S9. Representative low magnification TEM images of the samples shown in Figures 2 and 3.15

Figure S10. Vector-based caDNAno diagrams of 12HB DNA origami rod. .........................................16

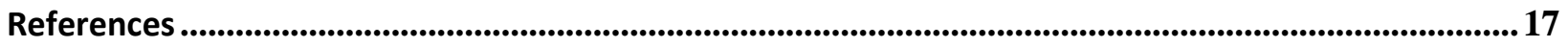


Abbreviations

\begin{tabular}{|l|l|}
\hline Abbreviation & Full name \\
\hline 12HB & 12 helix bundle \\
\hline BSA & bovine serum albumin \\
\hline CCD & charge-coupled device \\
\hline Chol & cholesterol \\
\hline DDM & n-dodecyl- $\beta$-D-maltoside \\
\hline DMSO & dimethyl sulfoxide \\
\hline DND & DNA-tethered nanodisc \\
\hline DOPC & 1,2-dioleoyl-sn-glycero-3-phosphocholine \\
\hline EDTA & ethylenediaminetetraacetic acid \\
\hline FPLC & fast protein liquid chromatography \\
\hline HEPES & 4-(2-hydroxyethyl)-1-piperazineethanesulfonic acid \\
\hline IDT & Integrated DNA Technologies Inc. \\
\hline MPB-PE & 1,2-dioleoyl-sn-glycero-3-phosphoethanolamine-N-[4-(p-maleimidophenyl)butyramide] \\
\hline MSP & membrane scaffold protein \\
\hline ND & nanodisc \\
\hline OG & n-octyl- $\beta$-D-glucopyranoside \\
\hline oligo & oligonucleotide \\
\hline PAGE & polyacrylamide gel electrophoresis \\
\hline PL & phospholipid \\
\hline SDS & sodium dodecyl sulfate \\
\hline SMCC & succinimidyl 4-(N-maleimidomethyl)cyclohexane-1-carboxylate \\
\hline SNARE & soluble NSF attachment protein receptor \\
\hline SSDNA & single-stranded DNA \\
\hline SUMO & small ubiquitin-like modifier \\
\hline TCEP & (tris(2-carboxyethyl)phosphine) \\
\hline TEM & transmission electron microscopy \\
\hline TMD & transmembrane domain \\
\hline
\end{tabular}




\section{Materials and Methods}

\section{Oligonucleotides \& Plasmids}

All DNA oligonucleotides were purchased from Integrated DNA Technologies (IDT). Unmodified DNA oligonucleotides for DNA origami were purchased as desalted solutions in 96-well plates. The sequences of handles and anti-handles were generated by NUPACK and their orthogonality was verified ${ }^{1}$. The following modified oligonucleotides were purchased as dry pellets and dissolved in Milli-Q water to yield the indicated concentrations:

\begin{tabular}{|l|l|l|l|}
\hline Name & Sequence & $\boldsymbol{\mu M}$ & Reaction \\
\hline Chol-Oligo1 & 5'-/5Chol-TEG/GTGAGTTGTGGTAGATAATTT-3' & 100 & $\mathbf{( 1 )}$ \\
\hline Oligo1-Chol & 5'-GTGAGTTGTGGTAGATAATTT/3CholTEG/-3' & 100 & \\
\hline Thiol-Oligo1 & 5'-/5ThioMC6-D/GTGAGTTGTGGTAGATAATTT-3' & 1000 & DNA-PL (2); \\
\hline Amine-Oligo1 & 5'-/5AmMC6/GTGAGTTGTGGTAGATAATTT-3' & 2000 & DNA-TMD (3); DNA-MSP (4) \\
\hline Amine-Oligo2 & 5'-/5AmMC6/GCCGCAGGATACAGAATACG-3' & 2000 & MSP \\
\hline
\end{tabular}

A pET-SUMO vector (Invitrogen) containing SUMO-synaptobrevin-Cys ${ }^{2}$ (SUMO-Syb2) was provided by A. Rebane, Y. Zhang and J.E. Rothman (Yale University). A pET28a vector (EMD Biosciences) to express MSP (MSP1E3D1 for 13-nm ND³) was acquired from Addgene (\#20066).

Mutagenesis was performed using a Q5 Site-Directed Mutagenesis Kit (NEB) as instructed by the manufacturer. In the case of SUMO-Syb2, the 96 amino acids that comprise the cytoplasmic domain of Syb2 were deleted, leaving only the TMD following the SUMO tag (with two serine residues as the linker). Note that in order to have only a single cysteine at the C-terminus of this construct, a native cysteine at position 128 in the TMD, was substituted with a serine residue. In the case of the MSP, a single amino acid change of $E 247 \underline{C}$ was made. Both proteins also have a His 6 fusion tag on their $\mathrm{N}$-termini. The sequences of both proteins are provided below (only one cysteine present in each protein):

\begin{tabular}{|l|l|}
\hline Sequence & Reaction \\
\hline MGSSHHHHHHGSGLVPRGSASMSDSEVNQEAKPEVKPEVKPETHINLKVSDGSSEIFFKIKKTT & DNA-TMD (3) \\
PLRRLMEAFAKRQGKEMDSLRFLYDGIRIQADQTPEDLDMEDNDIIEAHREQIGGSSIILGVISAII & \\
LIIIVYFSTC & \\
\hline MGHHHHHHHDYDIPTTENLYFQGSTFSKLREQLGPVTQEFWDNLEKETEGLRQEMSKDLEEVK & DNA-MSP (4) \\
AKVQPYLDDFQKKWQEEMELYRQKVEPLRAELQEGARQKLHELQEKLSPLGEEMRDRARAHV & \\
DALRTHLAPYLDDFQKKWQEEMELYRQKVEPLRAELQEGARQKLHELQEKLSPLGEEMRDRAR & \\
AHVDALRTHLAPYSDELRQRLAARLEALKENGGARLAEYHAKATEHLSTLSEKAKPALCDLRQGL & \\
LPVLESFKVSFLSALEEYTKKLNTQ & \\
\hline
\end{tabular}

\begin{tabular}{|l|l|l|l|}
\hline Protein & Molecular Weight (kDa) & DNA-protein conjugate & Molecular Weight (kDa) \\
\hline TMD-SUMO & 16 & DNA-TMD (3) & 22 \\
\hline MSP & 33 & DNA-MSP (4) & 39 \\
\hline
\end{tabular}




\section{Preparation of DNA-PL (2)}

The DNA-lipid conjugate was prepared using a previously established protocol, with minor modifications ${ }^{4}$. Briefly, $50 \mu \mathrm{l}$ of $1 \mathrm{mM}$ thiol-modified DNA oligonucleotides ( $5^{\prime}$ thiol modifier C6 S-S) were treated with 2 $\mu \mathrm{l}$ of $500 \mathrm{mM}$ TCEP (20:1 for TCEP:S-S) for 30 minutes, and immediately added to $1 \mu \mathrm{mol}$ of pre-dried MPBPE (20:1 for maleimide:thiol-oligo) in cross-linking buffer ( $25 \mathrm{mM} \mathrm{HEPES}-\mathrm{KOH} \mathrm{pH} \mathrm{7.4,} 140 \mathrm{mM} \mathrm{KCl}$ ) with 2\% $\mathrm{OG}$ at room temperature for 30 minutes. The reaction mixture was then diluted 2 -fold, added to $2.5 \mu \mathrm{mol}$ of pre-dried DOPC, and the OG concentration was increased to 4\%; samples were then dialyzed overnight in order to incorporate lipidated DNA molecules into liposomes. The conjugation products were separated from unconjugated DNA via isopycnic centrifugation in iodixanol gradients (0\%-36\%) and later analyzed by SDS-PAGE. In a typical gradient of $600 \mu \mathrm{l}$, the top 6 fractions ( $50 \mu \mathrm{l}$ each) were collected, combined, and concentrated by Amicon Ultra- $0.5 \mathrm{ml}$ Centrifugal Filters (3k). To remove free lipids from the conjugate, samples were mixed and vortexed with equal volume of 1-butanol for 1 minute, then centrifuged (12000 rpm or $30 \mathrm{~s}$ ) and recovered (lower aqueous layer). In some cases, DNA-lipid conjugates were further subjected to ethanol precipitation.

\section{Protein expression and purification}

We used established methods to express and purify SUMO-TMD and MSP5. Briefly, E. coli strain BL21-Gold (DE3) (Agilent) cells were grown in 2 liters of LB medium in a shaking incubator at $37{ }^{\circ} \mathrm{C}$ until the OD reached 0.6 , then protein expression was induced with $0.5 \mathrm{mM}$ IPTG for 4 hours at $37^{\circ} \mathrm{C}$. Cultures were then transferred to 2 liter bottles for centrifugation ( $5000 \mathrm{rpm}$ for $15 \mathrm{~min}$ ). Cell pellets were resuspended in $35 \mathrm{ml}$ of lysis buffer ( $25 \mathrm{mM}$ HEPES-KOH pH 7.4, $500 \mathrm{mM} \mathrm{NaCl}, 5 \%$ glycerol, $2 \mathrm{mM}$ TCEP, 0.02\% DDM) with one pill of complete EDTA-free protease inhibitor cocktail (Roche), and lysed by sonication in an icewater bath (1 s sonication $+1 \mathrm{~s}$ hold, $100 \%$ power, for 1 min total; this was repeated 2 times). The whole cell lysates were mixed with $3 \mathrm{ml}$ of $25 \%$ Triton X-100 (final concentration of $2 \% \mathrm{v} / \mathrm{v}$ ) and left on an endover-end rotator in cold room $\left(4^{\circ} \mathrm{C}\right)$ overnight.

The lysates were subjected to centrifugation (15,000 rpm for $45 \mathrm{~min}$ ) in a JA17 rotor (Beckman Coulter) at $4{ }^{\circ} \mathrm{C}$, and supernatants, containing the proteins of interest, were collected. The raw protein solution was then mixed with $3 \mathrm{ml}$ of pre-washed Ni Sepharose ${ }^{\mathrm{TM}} 6$ Fast Flow resin (GE), and put on an end-over-end rotator in a cold room for 1 hour. The slurry was transferred to a gravity column (Bio-rad Econo-Pac Chromatography Columns) and allowed to drain. The resin was then washed three times using $15 \mathrm{ml}$ of washing buffer (lysis buffer with $50 \mathrm{mM}$ imidazole), before elution with $6 \mathrm{ml}$ of elution buffer (25 mM HEPES-KOH pH 7.4, $150 \mathrm{mM} \mathrm{NaCl}, 5 \%$ glycerol, $0.5 \mathrm{mM}$ TCEP, 0.02\% DDM, $500 \mathrm{mM}$ imidazole). Optionally, the eluted proteins were further purified by an ÄKTA system (GE) using a FPLC column (Superdex 200 increase 10/300). Protein concentration was determined by staining SDS-PAGE gels with Coomassie Brilliant Blue R-250, using BSA as a standard. 


\section{Preparation of DNA-TMD (3) or DNA-MSP (4)}

DNA-protein conjugates were prepared using a previously described protocol, with some modifications ${ }^{6}$. In brief, free amines were removed from amine-modified oligonucleotides using an Amicon Centrifugal Filter (3k). Then $1 \mathrm{ml}$ of $10 \mathrm{mM} \mathrm{SMCC} \mathrm{(Thermo} \mathrm{Fisher)} \mathrm{in} \mathrm{DMSO} \mathrm{was} \mathrm{reacted} \mathrm{with} 0.5 \mathrm{ml}$ of $1 \mathrm{mM}$ amineoligo (20:1 for NHS:amine) in a total of $2.5 \mathrm{ml}$ of $100 \mathrm{mM}$ phosphate buffer (pH 7.4) for 1 hour at $37^{\circ} \mathrm{C}$. The product (maleimide-oligo) was purified by ethanol precipitation, and dissolved in Milli-Q water before use.

$50 \mathrm{nmol}$ of SUMO-TMD or MSP was first treated with $1 \mu$ l of 500 mM TCEP (10:1 for TCEP:Cys) for 1 hour at $4{ }^{\circ} \mathrm{C}$, then subjected to Amicon Ultra-4 Centrifugal Filter (3k) to remove the TCEP. The DNA-protein conjugation reaction occurred by mixing the maleimide-oligo with TCEP-treated proteins at a final concentration of $100 \mu \mathrm{M}$ and $10 \mu \mathrm{M}$ respectively (10:1 for maleimide:Cys) on an end-over-end rotator in a cold room overnight. Next, the mixture was added to $1 \mathrm{ml}$ of $\mathrm{Ni}$ Sepharose ${ }^{\mathrm{TM}} 6$ Fast Flow resin and put on an end-over-end rotator in a cold room for 1 hour. The slurry was transferred to a gravity column and washed three times using $5 \mathrm{ml}$ of washing buffer. DNA-protein conjugates and unconjugated protein bound to the resin, while unconjugated oligos were washed away. Three $\mathrm{ml}$ of elution buffer was added to elute the conjugation products.

The conjugation yield was measured in CBB-stained SDS-PAGE gels using ImageJ, and was calculated as the band intensity of DNA-protein conjugates (Pc) divided by total band intensity of conjugated (PC) and unconjugated $(\mathrm{Pu})$ proteins, i.e. Yield $=\mathrm{Pc} /(\mathrm{Pc}+\mathrm{Pu})$. Typical conjugation yield of DNA-TMD (3) and DNAMSP (4) ranged from $35 \%$ to $70 \%$. The yields of the particular batch shown in Figure $1 \mathrm{~d}$ was $41 \%$ for (3) and $64 \%$ for (4).

\section{Gel electrophoresis}

For characterization of the DNA moiety of the DNA-protein conjugates, $12 \%$ polyacrylamide gels with $0.1 \%$ SDS were cast in empty gel cassettes (Thermo Fisher). Samples mixed with SDS (final $2 \%, w / v$ ) and glycerol (final $5 \%, \mathrm{v} / \mathrm{v}$ ) were heated at $95{ }^{\circ} \mathrm{C}$ for $5 \mathrm{~min}$ before loading. After running at $200 \mathrm{~V}$ for $30 \mathrm{~min}$ in $1 \times \mathrm{TAE}$ buffer with $0.1 \%$ SDS, the gel was stained using SYBR ${ }^{\text {TM }}$ Gold (Thermo Fisher) for 1 hour and imaged.

For characterization of the protein moiety of the DNA-protein conjugates, two-layer polyacrylamide gels ( $12 \%$ resolving, $4 \%$ stacking) with $0.1 \%$ SDS were cast in empty gel cassettes. Samples mixed with SDS and glycerol, and were heated, as above, before loading onto gels. After running at $200 \mathrm{~V}$ for $50 \mathrm{~min}$ in $1 \times$ running buffer ( $25 \mathrm{mM}$ Tris, $190 \mathrm{mM}$ glycine, 0.1\% SDS), gels were stained with Coomassie Brilliant Blue R-250 for 2 hours and de-stained by $40 \%$ methanol and $10 \%$ glacial acetic acid for 4 hours before imaging.

\section{DND formation}

MSP and DOPC were mixed in a final concentration of $4 \mu \mathrm{M}$ and $400 \mu \mathrm{M}$ respectively (1:100 for MSP:lipid) in $1 \times$ reconstitution buffer ( $25 \mathrm{mM}$ HEPES-KOH pH 7.4, $100 \mathrm{mM} \mathrm{KCl} 1 \mathrm{mM} \mathrm{TCEP}$ ) containing 0.02\% DDM. For DND1-DND3, $2 \mu \mathrm{M}$ DNA-anchor amphiphiles (1)-(3) were spiked in the reaction (1:2 for DNA:MSP) without altering other components; For DND4, the MSP was replaced by equivalent DNA-MSP (4), while lipids and DDM remained unchanged. Then, DDM was removed by adding $25 \%$ volume of water- 
suspended Bio-Beads (Bio-Rad) and mixing samples end-over-end overnight at $4{ }^{\circ} \mathrm{C}$. NDs formed as the detergent is removed ${ }^{7}$, and the DNA-anchor complexes are incorporated into the NDs ${ }^{8}$. Afterwards, BioBeads were filtered out by applying the samples to DNA Gel Extraction Spin Columns (Bio-Rad), and the liquid going through the filter cup was subjected to FPLC (Superdex 200 increase 10/300) on a ÄKTA system. Relevant fractions corresponding to desired products were collected and stored at $-20^{\circ} \mathrm{C}$ before use.

\section{DNA origami design and preparation}

All DNA origami structures were designed using caDNAno software ${ }^{9}$. V-shaped origami ${ }^{10,11}$ and DNA nanocages ${ }^{12}$ were modified from published work, while the $12 \mathrm{HB}$ rod was built from scratch.

The DNA scaffold strand (8064-nt) was produced using E.coli and M13-derived bacteriophages ${ }^{13,14}$. Each DNA origami structure was assembled from a scaffold strand (50 nM) and a dedicated pool of synthetic staple strands ( $300 \mathrm{nM}$ each) in $1 \times$ folding buffer ( $5 \mathrm{mM}$ Tris $\bullet \mathrm{HCl}, 1 \mathrm{mM} \mathrm{EDTA}, 12.5$ or $18 \mathrm{mM}$ of $\mathrm{MgCl}_{2}$, $\mathrm{pH}$ 8.0) using a thermal annealing program $\left(58^{\circ} \mathrm{C}-50^{\circ} \mathrm{C}-18 \mathrm{~h}\right.$ for V-origami; $80^{\circ} \mathrm{C}-20^{\circ} \mathrm{C}-36 \mathrm{~h}$ for nanocages and rods). Correctly assembled DNA cages were purified via rate-zonal centrifugation in glycerol gradients as described previously ${ }^{15}$, and stored at $-20^{\circ} \mathrm{C}$ before use.

\section{Origami-directed DND patterning}

Typically, a 5-fold excess (compared to the number of handles on origami) of DNDs were incubated with purified origami at room temperature for 1 hour, then subjected to rate-zonal centrifugation in glycerol gradients. Agarose gel was used for identifying each fraction. In most instances, desired fractions were collected and concentrated by Amicon Centrifugal Filter (30k).

To make nanotubes out of nanocages, linker strands were added to ND-decorated nanocage monomers at a 20:1 molar ratio. The mixture was then annealed from $40{ }^{\circ} \mathrm{C}$ to $20^{\circ} \mathrm{C}$ overnight and imaged without further purification ${ }^{12}$.

\section{Negative stain TEM}

Five $\mu$ l samples were deposited on a glow-discharged formvar/carbon coated copper grid (Ted Pella, Inc.) for 1 minute, and liquid was blotted away using filter paper. The grid was subsequently washed with 7.5 $\mu \mathrm{l} 1 \times$ reconstitution buffer and stained with $7.5 \mu \mathrm{l} 1 \%(\mathrm{w} / \mathrm{v})$ uranyl formate for 1 minute. Images were acquired using an FEI Tecnai T12 TEM (120 kV) equipped with an EDS detector and 4k x 4k Gatan Ultrascan CCD. 


\section{Supplementary Tables}

Table S1. Attachment yield and specificity of single DNDs on V-origami.

\begin{tabular}{|c|c|c|c|c|c|c|c|}
\hline DND type & $\#$ & Successful & Incorrect & Missing & Yield & Specificity & Figure \\
\hline DNA-Chol-ND (5') & DND1 & 141 & 0 & 37 & $79 \%$ & $100 \%$ & 2a \& S2 \\
\hline DNA-PL-ND & DND2 & 127 & 0 & 24 & $84 \%$ & $100 \%$ & 2a \& S2 \\
\hline DNA-TMD-ND & DND3 & 159 & 3 & 17 & $89 \%$ & $98 \%$ & 2a \& S2 \\
\hline DNA-MSP-ND & DND4 & 112 & 1 & 32 & $77 \%$ & $99 \%$ & 2a \& S2 \\
\hline & & & & & & & \\
\hline DNA-Chol-ND (5') & DND1 & 103 & 0 & 26 & $80 \%$ & $100 \%$ & S5 \\
\hline DNA-Chol-ND (3') & & 108 & 0 & 25 & $81 \%$ & $100 \%$ & S5 \\
\hline & & & & & & & \\
\hline DND4-oligo1 & DND4 & 73 & 0 & 20 & $78 \%$ & $100 \%$ & $3 \mathrm{~b}$ \\
\hline DND4-oligo2 & & 51 & 0 & 20 & $72 \%$ & $100 \%$ & $3 \mathrm{~b}$ \\
\hline
\end{tabular}




\section{Supplementary Figures}
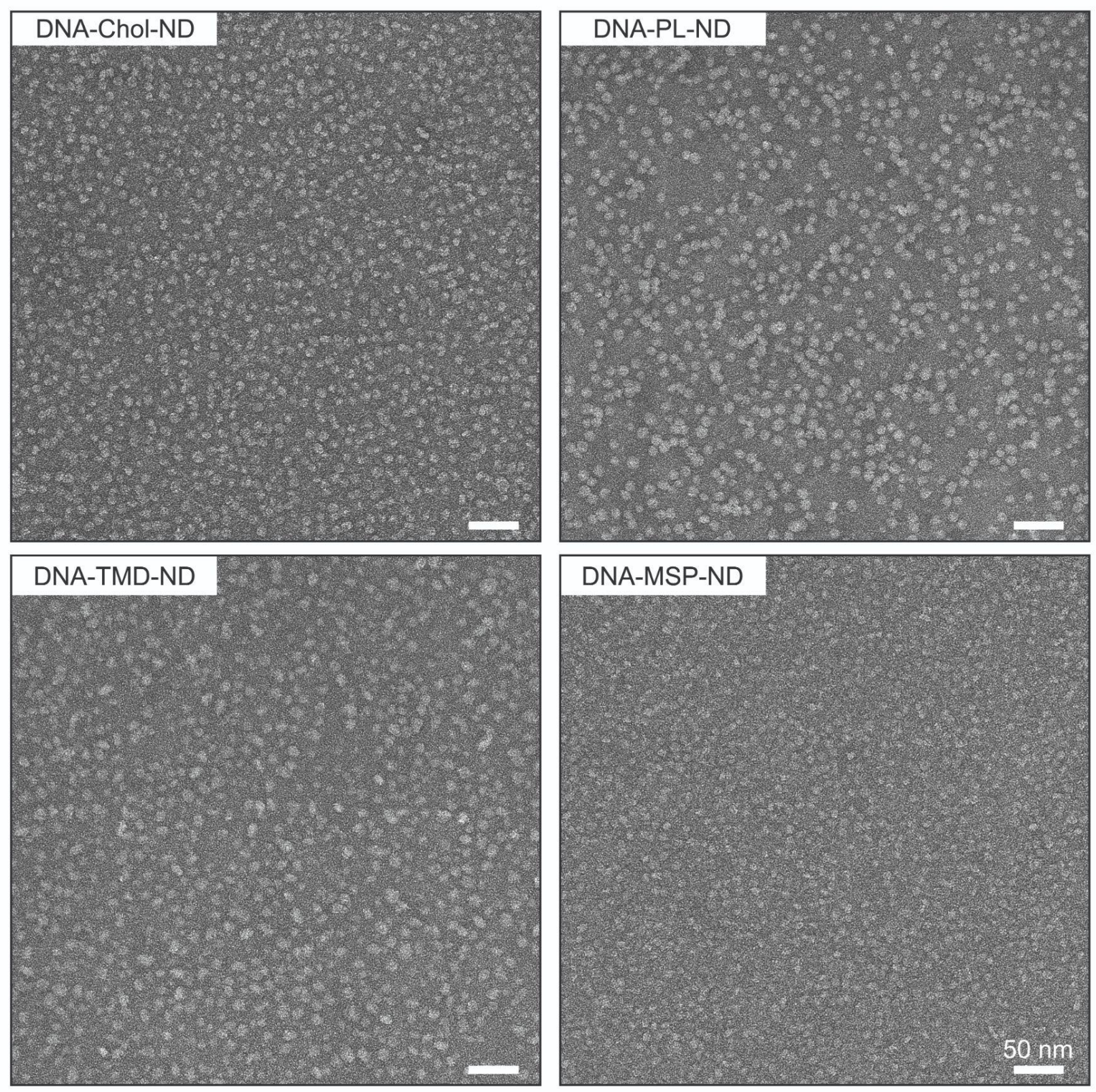

\section{Figure S1. TEM images of DNDs.}

Four types of DNDs (numbered as DND1-DND4 in the paper), constructed with corresponding DNA-anchor amphiphiles ((1)-(4)), were examined by TEM. One representative image was shown for each DND type. Homogeneous circular particles were seen across all types, indicating proper formation of ND. Scale bars: $50 \mathrm{~nm}$. 


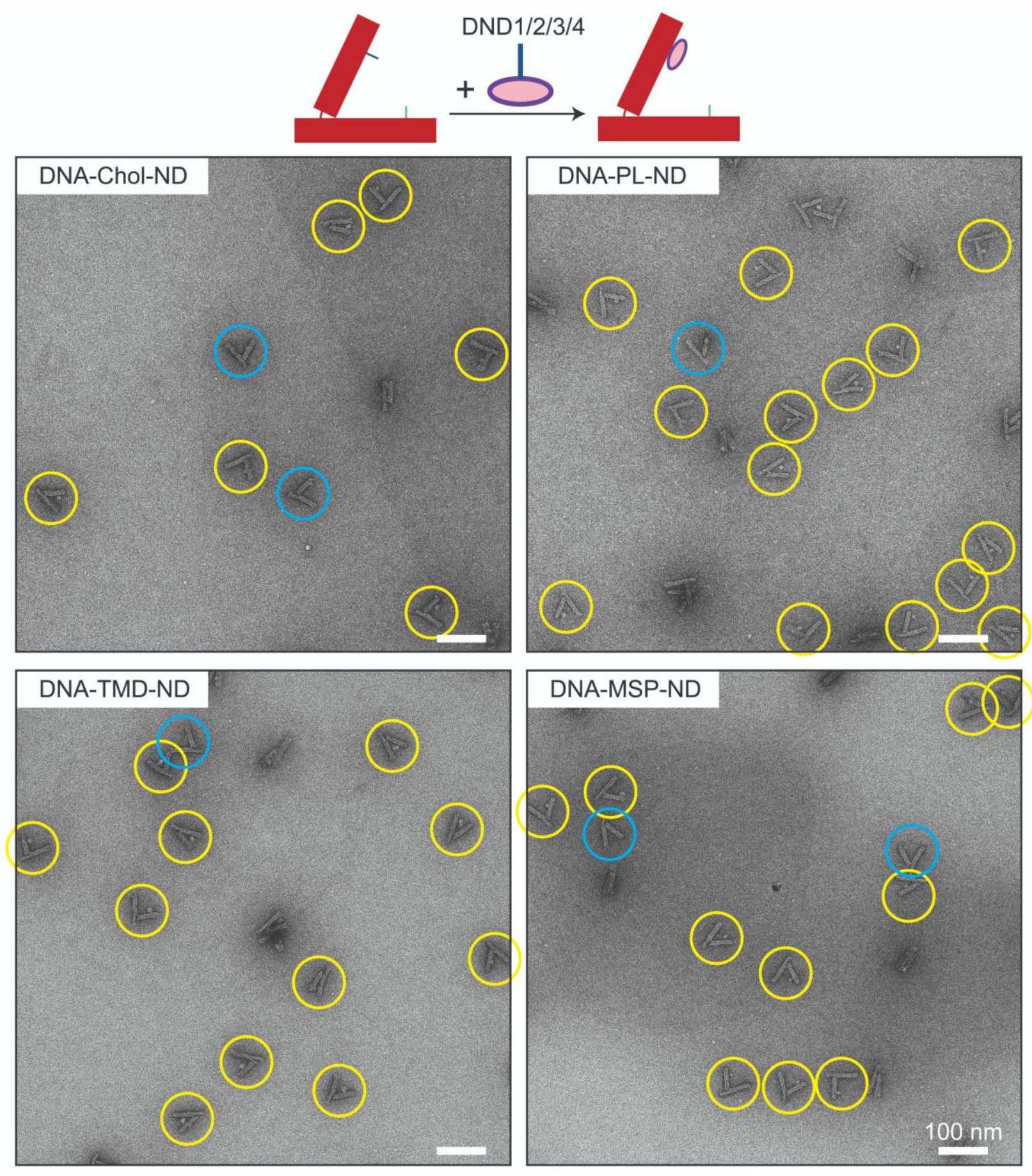

Figure S2. TEM images of DND on V-origami for yield analysis.

A representative image, with circled V-origami structures, is shown for each type of DND. Successful events were marked as yellow circles, while blue circles highlight V-origami without discernable NDs. Malformed V-origami and occasionally ND-mediated oligomers (see one example in the top right image) were discarded from analysis. See statistics in Table S1. Scale bars: $100 \mathrm{~nm}$. 
a
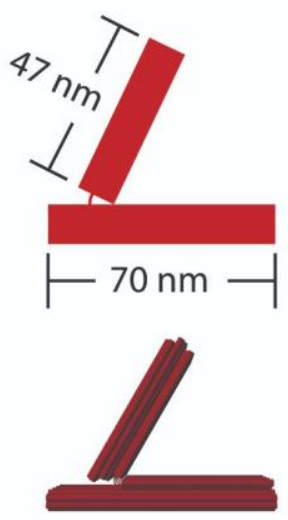

b
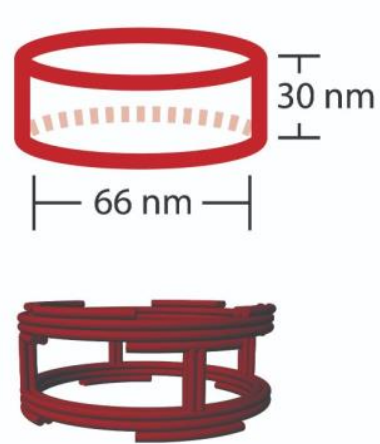

C
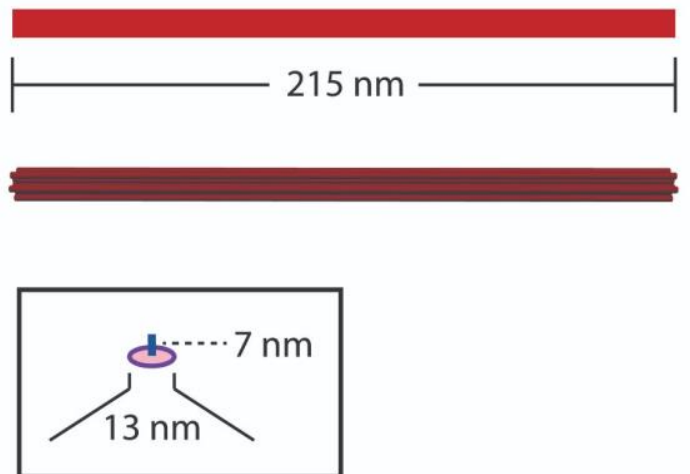

Figure S3. Schematics of DNA origami design.

2D/3D Models drawn by Illustrator (top) and Maya (bottom) were shown for each origami structure. All models were drawn approximately in scale. (a) A V-shaped DNA origami with one short arm (47 nm) and one long arm $\left(70 \mathrm{~nm}\right.$ ) connected by an array of ssDNA (scaffold loops) ${ }^{11}$. (b) A cylindrical DNA nanocage with two rings (inner diameter: $66 \mathrm{~nm}$ ) connected by four pillars (total height: $30 \mathrm{~nm}$ ) ${ }^{12}$. (c) A 12HB DNA rod with total length of $215 \mathrm{~nm}$. Inset: A 13-nm ND tethered by an extended 21-nt DNA single strand used in this study is also included for comparison. 
a

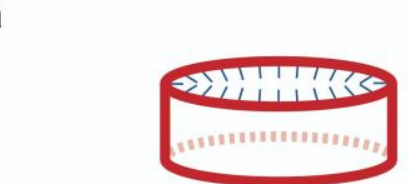

DNA-X

$(1) /(2) /(3) /(4)$

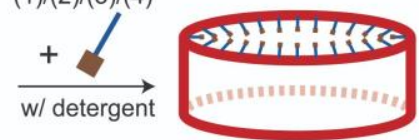

+ DNA-Chol (1)

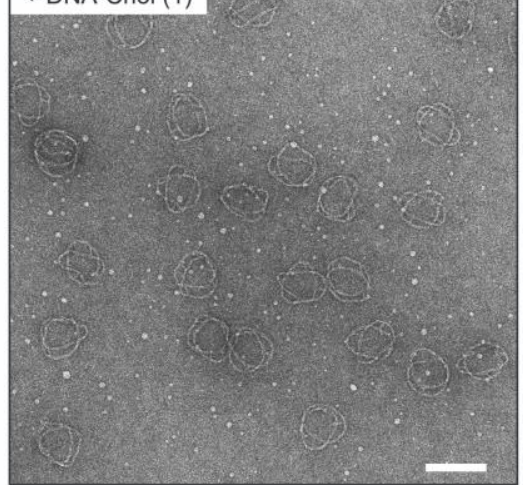

+ DNA-TMD (3)

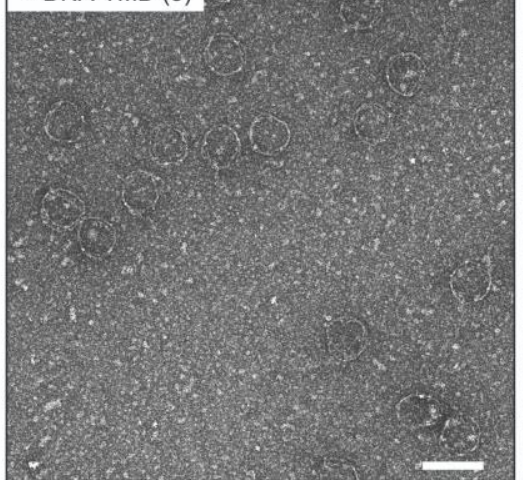

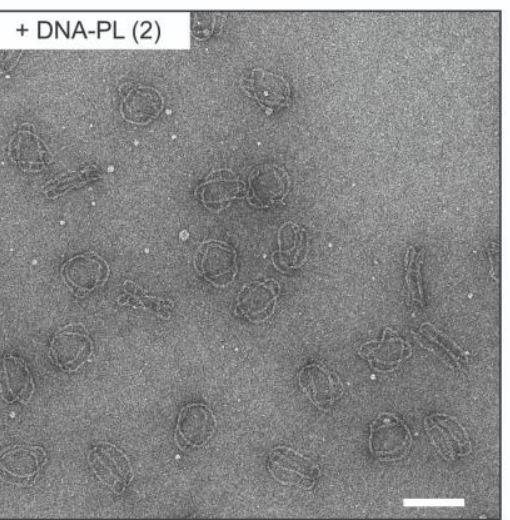

+ DNA-MSP (4)

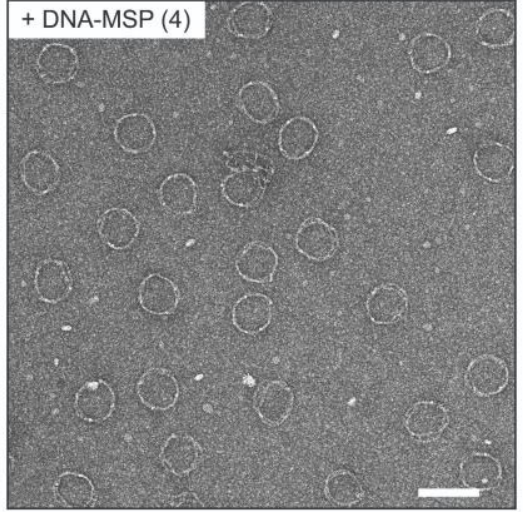

b
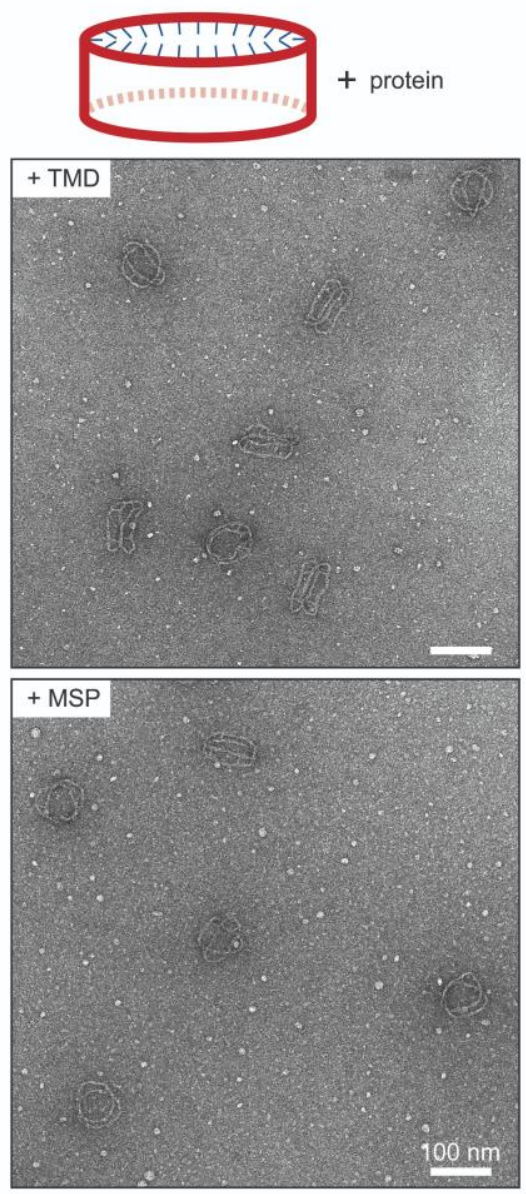

Figure S4. Anchor proteins require handles in order to bind DNA cages.

Four types of DNA-anchor amphiphiles ((1)-(4)) (a), and two types of anchor proteins that lacked DNA handles (b), were incubated with DNA nanocage respectively (10:1 in stoichiometry), in the presence of $0.04 \%$ DDM. The samples were examined by TEM without purification. One representative image is shown for each condition. Scale bars: $100 \mathrm{~nm}$. White particles (diameter $<20 \mathrm{~nm}$ ) were scattered in the background of all the images; these are likely to be (DNA-)protein-detergent micelles. Some of (3) and (4) were also observed at the inner side of DNA rings (bottom row in (a)), due to hybridization between exposed anti-handles in the micelles and handles on origami. Importantly, there was no apparent enrichment of micelle particles on the body of DNA origami in (b), where the anchors lacked handles, indicating that non-specific binding between the anchor molecules and the origami does not occur. 


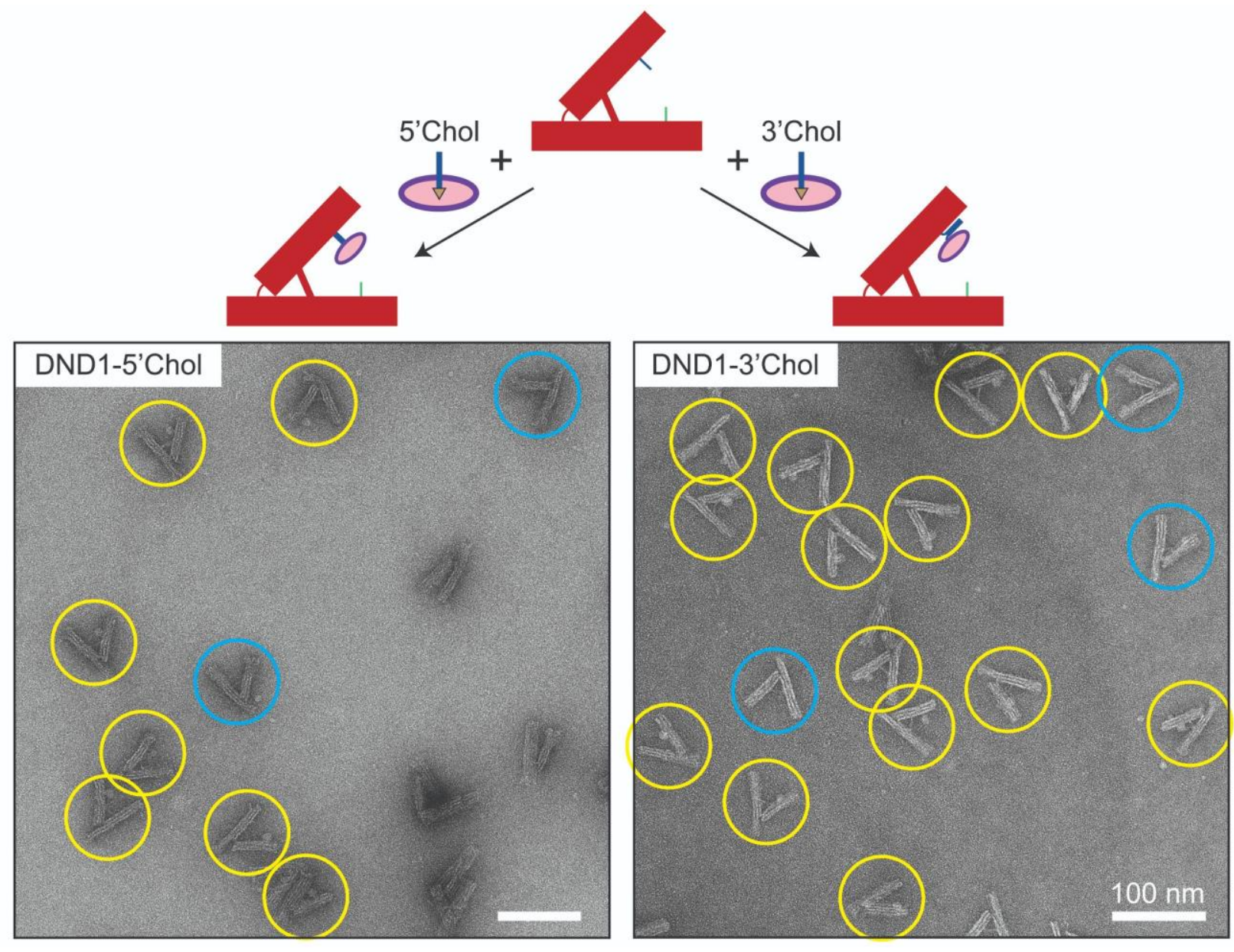

Figure S5. Comparison of DND with 5'- and 3'- modified oligos attaching to V-origami.

Because the handles were extended from the $3^{\prime}$ end of oligos on origami, a DND with 5'-modified antihandle would reside in the opposite end of a DNA duplex (spacer-like configuration) to the origami body upon hybridization. Similarly, a DND with 3'-modified anti-handle would attach to the same end of a DNA duplex (zipper-like configuration) as the origami. One representative TEM image with circled V-origami was shown for each type of DND. Successful events were marked as yellow circles while blue circles highlight V-origami structures without a discernable ND. Malformed V-origami were not included in our analysis. See statistics in Table S1. No apparent differences in either the attachment yield or apparent location, were observed between the two configurations at this level of image resolution. Scale bars: 100 $\mathrm{nm}$. 


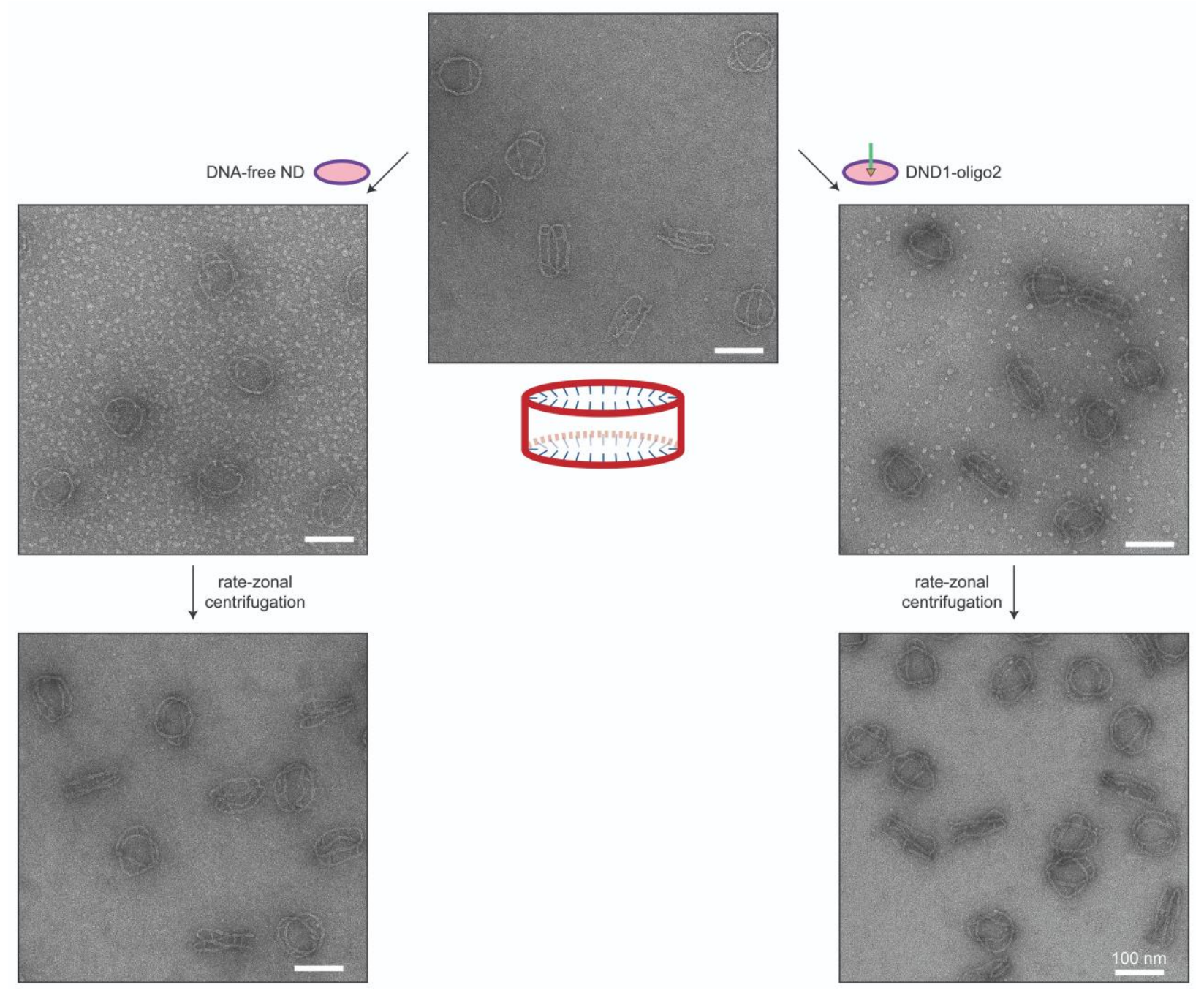

Figure S6. TEM images of DNA nanocages with control DNDs.

DNA nanocages with handles on both rings were incubated with DNA-free NDs (left pathway) or DND1 with non-complementary oligos (right pathway). Almost no NDs were observed on origami after rate-zonal centrifugation purification (bottom row), stressing the importance of specific DNA tethers on NDs for highorder assembly onto origami. One representative TEM image was shown for each condition. Scale bars: $100 \mathrm{~nm}$. 
a
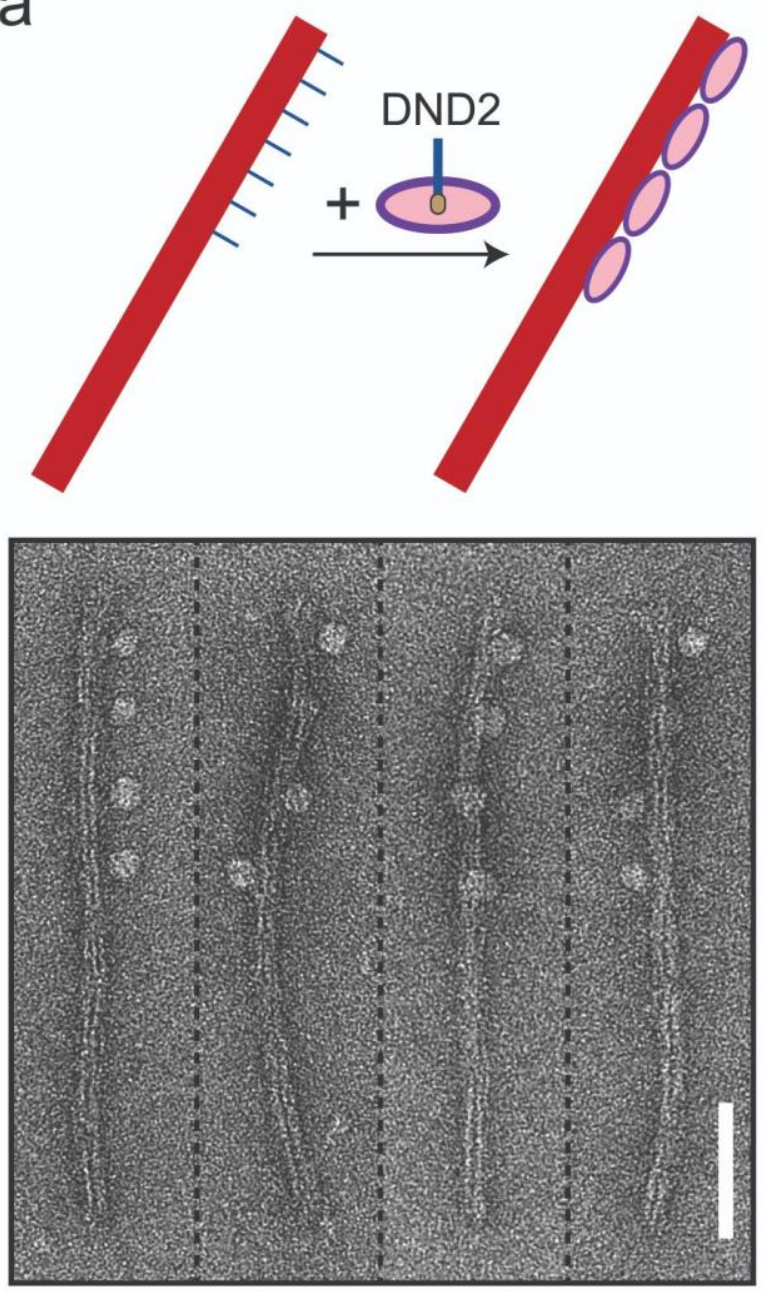

b
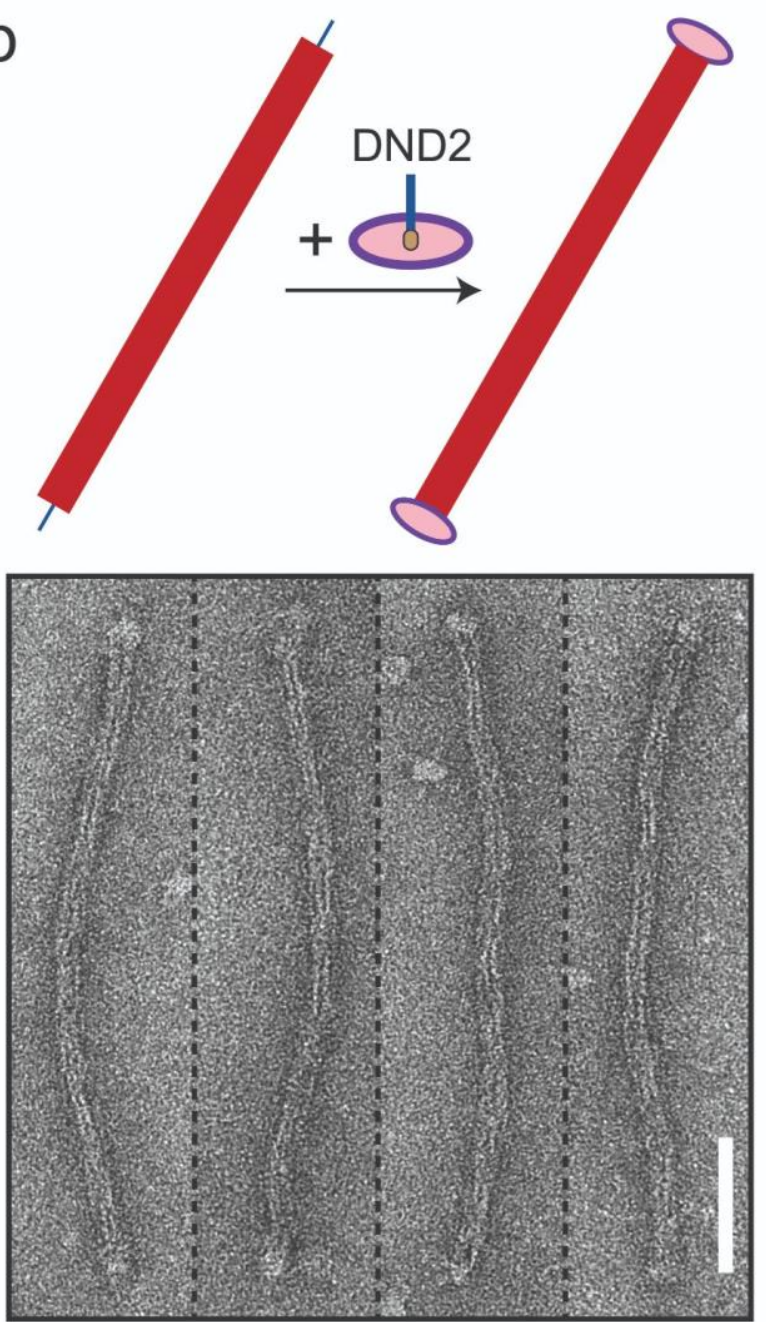

Figure S7. DND patterning on rod origami.

12HB DNA rod origami with handles on half of one side (a) or two ends (b) were used to template DND2. Schematics (top) and representative cropped TEM images (bottom) were shown in each case. Scale bars: $50 \mathrm{~nm}$. 

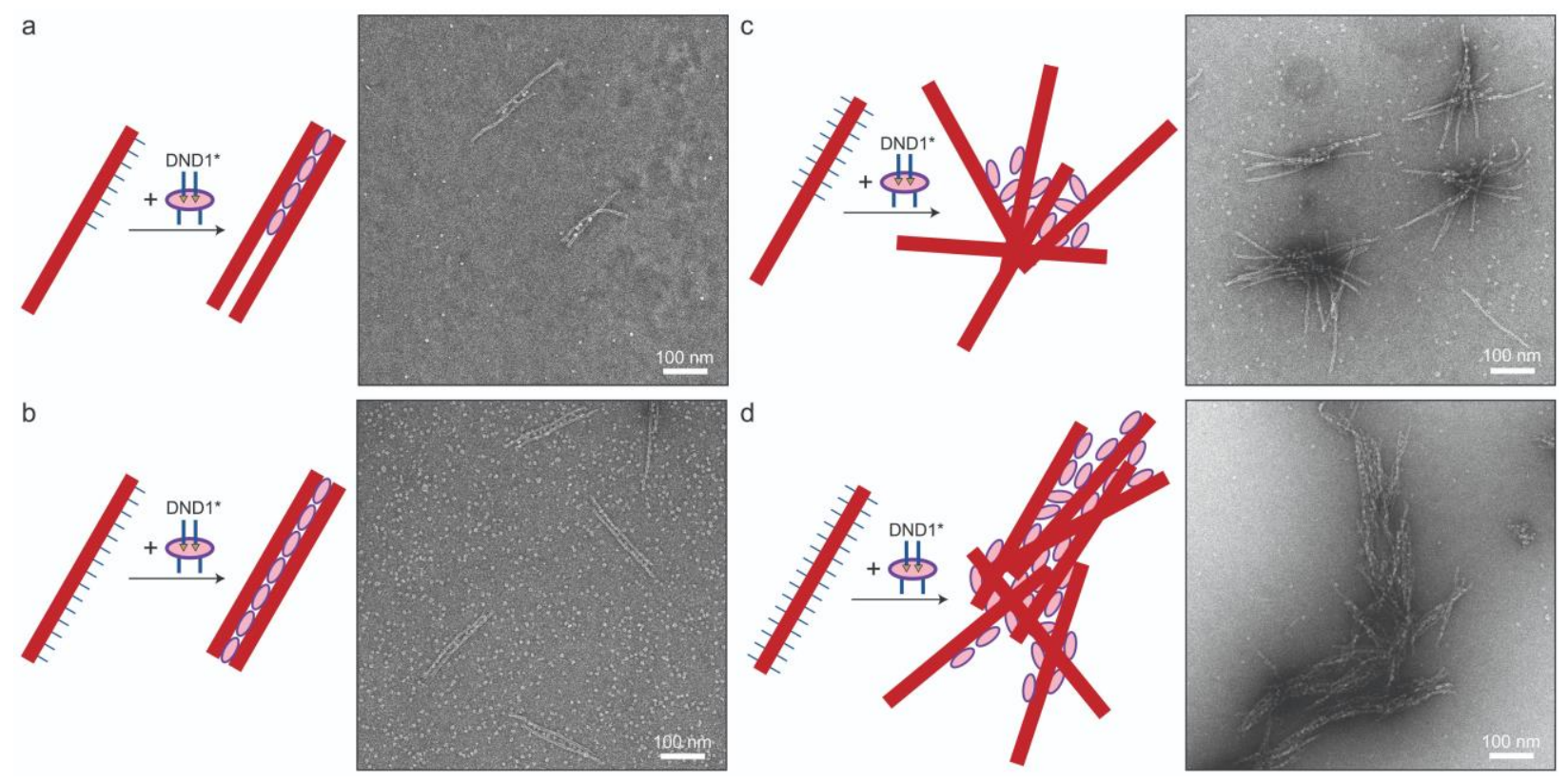

Figure S8. DND-mediated rod assembly.

DNDs with multiple Chol-modified oligos (DND1*) bridge the origami rods with side handles. (a) \& (b): Handles on half (a) or all (b) of one side. A typical product here was a line of NDs sandwiched by two rods. (c) \& (d): Handles on half (c) or all (d) of two opposite sides. The majority of the rods formed aggregates with parallel or radial patterns, mediated by DNDs. Schematics (top) and a representative TEM image (bottom) are shown for each case. Scale bars: $100 \mathrm{~nm}$. 
a
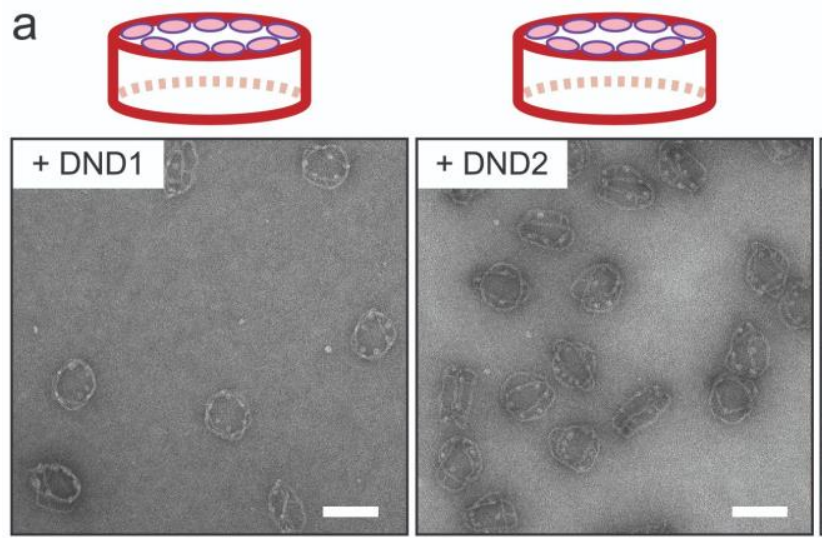

b
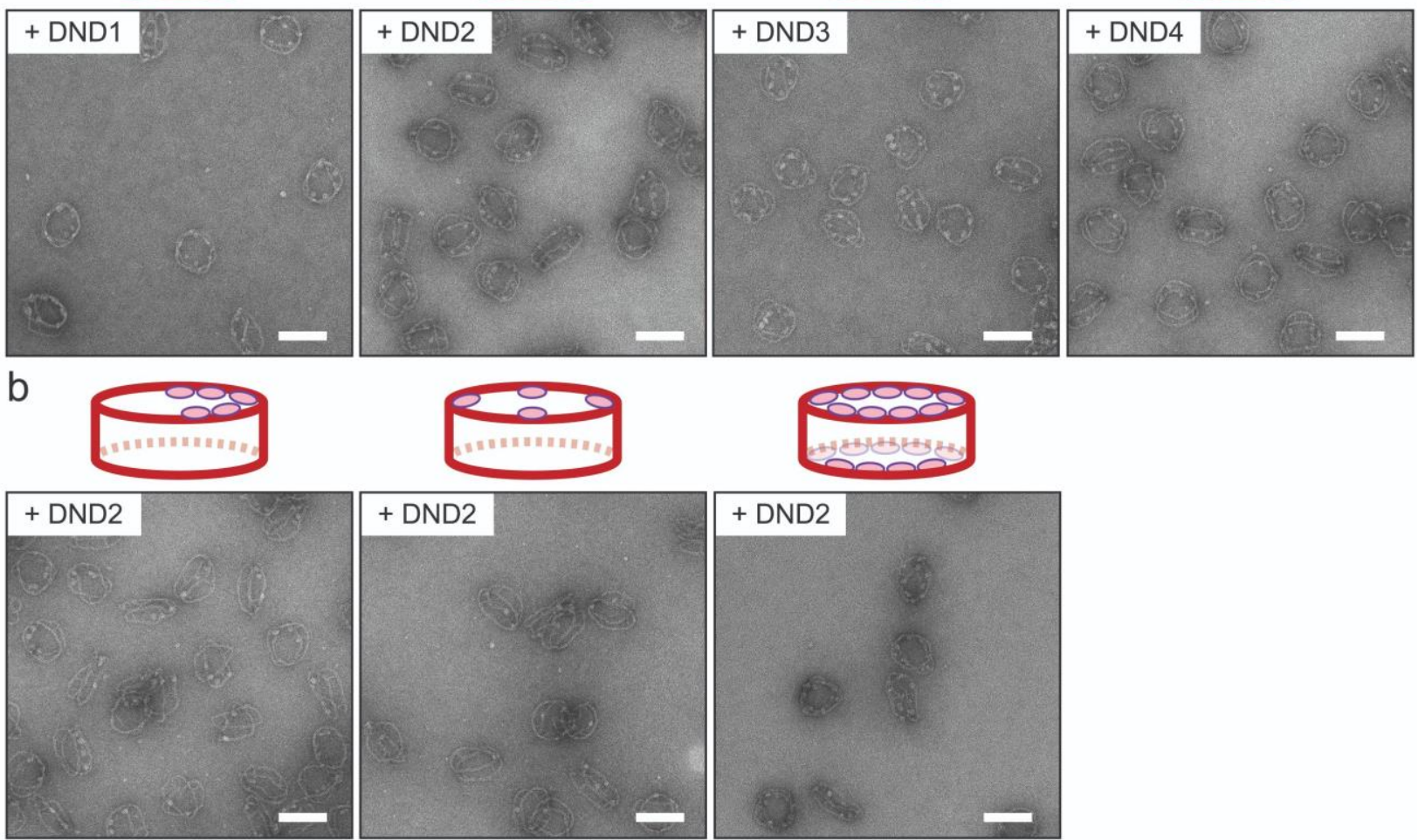

C
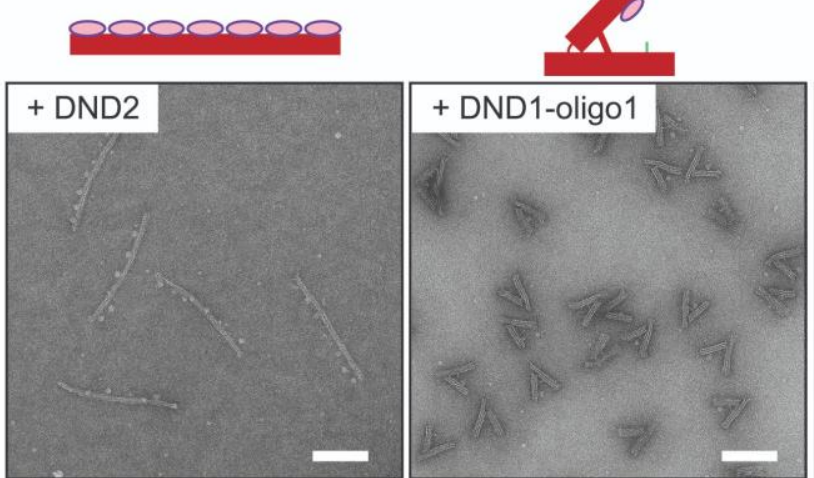
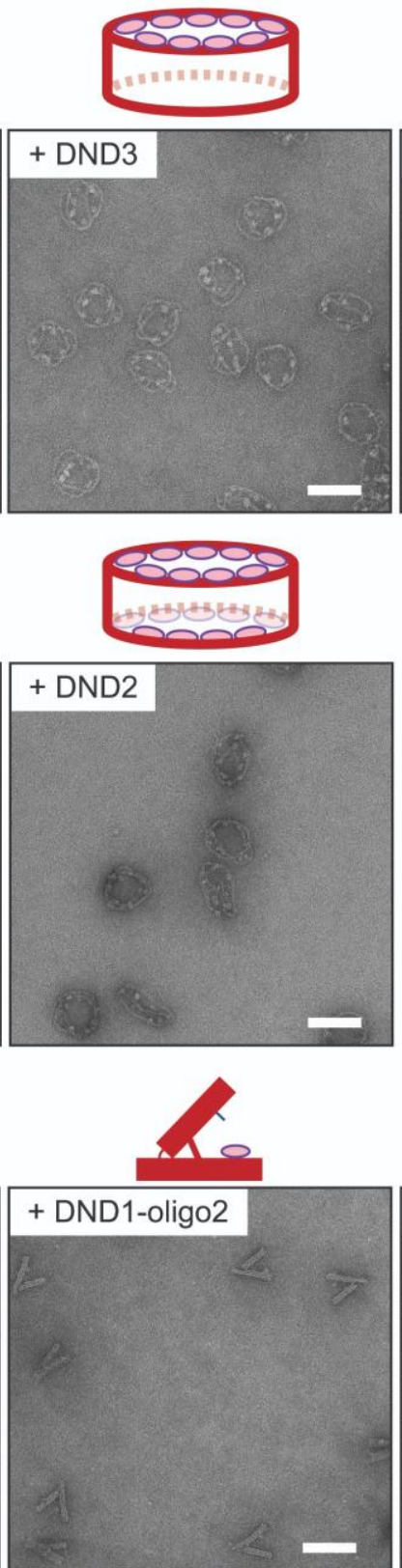

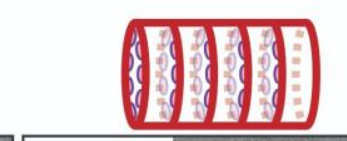

+ DND4

Figure S9. Representative low magnification TEM images of the samples shown in Figures $\mathbf{2}$ and $\mathbf{3}$.

(a): Figure 2 b. (b): Figure 2c. (c): Figure 3a-c. Scale bars: $100 \mathrm{~nm}$. 


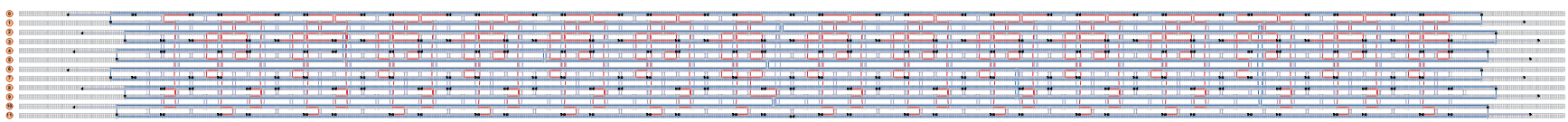

scaffold

core staples

staples having the option of carrying handles

Figure S10. Vector-based caDNAno diagrams of 12HB DNA origami rod.

A subsets of staples carrying handles combined with the no-handle version of its complementary subset to form desirable structure variants. Extensions from the ends of rod were a string of thymidines attached to the $3^{\prime}$ end of corresponding core staples. 


\section{References}

(1) Zadeh, J. N.; Steenberg, C. D.; Bois, J. S.; Wolfe, B. R.; Pierce, M. B.; Khan, A. R.; Dirks, R. M.; Pierce, N. A. NUPACK: Analysis and design of nucleic acid systems. J. Comput. Chem. 2011, 32, 170-3.

(2) Gao, Y.; Zorman, S.; Gundersen, G.; Xi, Z.; Ma, L.; Sirinakis, G.; Rothman, J. E.; Zhang, Y. Single reconstituted neuronal SNARE complexes zipper in three distinct stages. Science 2012, 337, 1340-3.

(3) Denisov, I. G.; Baas, B. J.; Grinkova, Y. V.; Sligar, S. G. Cooperativity in cytochrome P450 3A4 - Linkages in substrate binding, spin state, uncoupling, and product formation. J. Biol. Chem. 2007, 282, 7066-7076.

(4) Yang, Y.; Wang, J.; Shigematsu, H.; Xu, W.; Shih, W. M.; Rothman, J. E.; Lin, C. Self-assembly of sizecontrolled liposomes on DNA nanotemplates. Nat. Chem. 2016, 8, 476-83.

(5) Bao, H.; Goldschen-Ohm, M.; Jeggle, P.; Chanda, B.; Edwardson, J. M.; Chapman, E. R. Exocytotic fusion pores are composed of both lipids and proteins. Nat. Struct. Mol. Biol. 2016, 23, 67-73.

(6) Harrison, J. G.; Balasubramanian, S. Synthesis and hybridization analysis of a small library of peptideoligonucleotide conjugates. Nucleic Acids Res. 1998, 26, 3136-45.

(7) Bayburt, T. H.; Grinkova, Y. V.; Sligar, S. G. Self-assembly of discoidal phospholipid bilayer nanoparticles with membrane scaffold proteins. Nano Lett. 2002, 2, 853-856.

(8) Bayburt, T. H.; Sligar, S. G. Self-assembly of single integral membrane proteins into soluble nanoscale phospholipid bilayers. Protein Sci. 2003, 12, 2476-2481.

(9) Douglas, S. M.; Marblestone, A. H.; Teerapittayanon, S.; Vazquez, A.; Church, G. M.; Shih, W. M. Rapid prototyping of 3D DNA-origami shapes with caDNAno. Nucleic Acids Res. 2009, 37, 5001-6.

(10) Funke, J. J.; Dietz, H. Placing molecules with Bohr radius resolution using DNA origami. Nat. Nanotech. 2016, 11, 47-52.

(11) Funke, J. J.; Ketterer, P.; Lieleg, C.; Schunter, S.; Korber, P.; Dietz, H. Uncovering the forces between nucleosomes using DNA origami. Sci. Adv. 2016, 2, e1600974.

(12) Zhang, Z.; Yang, Y.; Pincet, F.; Llaguno, M. C.; Lin, C. Placing and shaping liposomes with reconfigurable DNA nanocages. Nat. Chem. 2017, 9, 653-659.

(13) Douglas, S. M.; Dietz, H.; Liedl, T.; Hogberg, B.; Graf, F.; Shih, W. M. Self-assembly of DNA into nanoscale three-dimensional shapes. Nature 2009, 459, 414-8.

(14) Dietz, H.; Douglas, S. M.; Shih, W. M. Folding DNA into twisted and curved nanoscale shapes. Science 2009, 325, 725-30.

(15) Lin, C.; Perrault, S. D.; Kwak, M.; Graf, F.; Shih, W. M. Purification of DNA-origami nanostructures by rate-zonal centrifugation. Nucleic Acids Res. 2013, 41, e40. 